\title{
AECT Instructional Design Standards for Distance Learning
}

\author{
Anthony A. Piña ${ }^{1}$ \\ Published online: 28 March 2018 \\ (C) Association for Educational Communications \& Technology 2018
}

\begin{abstract}
AECT's Vision Statement states, "We seek to be the premier international organization in educational technology, the organization to which others refer for research and best practices" (AECT 2018). The fall 2017 publication of the AECT Instructional Design Standards for Distance Learning (Piña 2017) is a watershed event for our Association and a leap forward in achieving the vision.
\end{abstract}

\section{How Did the AECT Standards Come to be?}

"Standards provide people and organizations with a basis for mutual understanding, and are used as tools to facilitate communication, measurement, commerce and manufacturing" (CEN-CENELEC 2018, p.1). The Instructional Design Standards for Distance Learning began as a series of discussions between AECT members and AECT staff regarding the prevalence of online courses being developed at higher education institutions without the guidance of research based standards for designing online learning (Harris 2017). "Working from the extensive research literature on instructional design, two AECT members drafted the standards, and an edited version was approved by AECT's Executive Committee and shared with selected members of the Division of Distance Learning. Once all comments had been addressed, they were presented to the full Board of Directors, and they too approved them" (Harris 2017, p. 1).

Once the standards had been approved, several leading AECT scholars and practitioners were invited to flesh out the standards and to provide evidence and justification for their use. A series of sample rubrics also were developed. Those who contributed to this effort were Saul Carliner, Yuan Chen, Peggy Ertmer, Phil Harris, Yi-Chun Hong, Judith Lewandowski, Michael Molenda, Gary Morrison,

Anthony A. Piña

APina@ sullivan.edu

1 Sullivan University, Louisville, KY, USA
Jennifer Morrison, Anthony Piña, David Price, Jennifer Richardson, Steven Ross, Wilhelmina Savenye, and Michael Simonson.

\section{How do the AECT Standards Compare to Other Existing Standards?}

Useful standards and tools related to instructional design and distance learning have been formulated by the International Board of Standards for Training, Performance and Instruction (ibstpi), Quality Matters (QM) and the Online Learning Consortium (OLC). The focus of the ibstpi standards is upon competencies that can be demonstrated by instructors, instructional designers, evaluators, training managers and online learners (Klein et al. 2004; Kozalka et al. 2013). The Higher Education Course Design Rubric by QM and the OSCQR Course Design Review Scorecard by OLC are comprehensive tools providing a large number of assessment items by which the features of online and blended/hybrid courses can be evaluated and improved (Online Learning Consortium 2018; Piña and Bohn 2014; Quality Matters 2014).

The AECT Instructional Design Standards for Distance Learning are intended to inform and provide guidance before, during and after the design and development of online and blended/hybrid courses. They can be used in tandem with other tools to assure that empirically sound principles of learning and instruction are "baked" into courses designed for learners at a distance. There is also a set of accompanying sample rubrics that have been developed for practical application of the standards.

\section{What are the Standards?}

- Purpose. Effective course design begins with a clearly articulated purpose. This is the standard to which all other standards must align. Purpose may be thought of as twodimensional: institution or instructor and student. The 
design should include both the purpose of the course as envisioned by the institution or instructor and the purpose as viewed by the student. As the purpose is articulated through goals and objectives, collaboration between instructor and student will set a firmer foundation than can be achieved through a one-dimensional purpose statement.

- Assumptions. Course design must take into account assumptions that shape the purpose and subsequent course development. Most assumptions are based on students' prior knowledge and established understandings and skills. Articulating these content assumptions provides a starting point for new learning. Assumptions in the case of online learning also encompass students' ability to use delivery technology.

- Sequence. Learning opportunities must be sequenced in a manner that promotes efficient knowledge acquisition consistent with the prior-knowledge assumptions. Various models of sequencing-linear, spiral, scaffold, etc. - should be considered, and the course design should incorporate those strategies best suited to the content within the constraints of online delivery.

- Activities. Learning is achieved through activities both passive (reading, listening, viewing) and active (experimenting, rehearsing, trying). Activities should be chosen that best suit the content, students' levels of knowledge, experience, and ability, and online delivery constraints, particularly accommodating synchronous, asynchronous, and mixed course participation. Student selfselected or self-developed learning activities should be incorporated along with instructor-selected and instructor-developed activities, consistent with a twodimensional purpose.

- Resources. A range of resources should be articulated to foster deep learning and extend course-centered experiences and activities. Resources should be multimodal to accommodate students' interests, understandings, and capacities, consistent with course content and technological accessibility. Resources should allow students to go beyond the constraints of the formal course structure to engage in self-directed, extended learning.

- Application. Consistent with providing for active learning, students should have integral opportunities within the course design to apply new learning. Effective course design incorporates opportunities to practice newly acquired understandings and skills, both independently and collaboratively. Online collaborative application opportunities should be developed using social media, and offline collegial groups also should be structured whenever physical proximity of students affords this opportunity.

- Assessment. Regardless of the model of sequencing learning opportunities, the sequence should include points of assessment for purposes of feedback and review, with instances of re-teaching as necessary for students to acquire full understanding. Formative assessment, whether formal, informal, or incidental, allows teachers and students to give feedback to one another and to review the operationalized design in order to revise the course design based on students' input with regard to knowledge acquisition and effective use of new understandings and skills.

- Reflection. Effective course design must include opportunities for reflection as an extension of the Feedback/ Review/Reteach standard. Reflection involves both instructor self-reflection and student self-reflection related to achievement of the purposes that have been articulated as the basis for the course. Such reflection is intended to deepen the learning experience and may serve as reiteration of purpose at key points during the course.

- Independent Learning. Effective course design incorporates opportunities for independent learning, both instructor- and self-directed. Online course development, particularly in the asynchronous mode, should epitomize independent learning, which should include opportunities for feedback, review, and reflection - all of which should resonate with the purpose.

- Evaluation. Course evaluation must be purpose-driven. Alignment with the purpose should be threefold: a) based on acquisition of new knowledge, understandings, and skills; b) based on instructor self-evaluation; and c) based on student self-evaluation. Multidimensional evaluation offers a fully articulated basis for judging the success of the course and the students as well as providing information that can help shape future iterations of the course.

\section{Where can I Access a Copy of the Rationale and Rubrics for the Standards?}

Members of AECT have access to an e-book version of Instructional Design Standards for Distance Learning (Piña 2017) through the publications area of the AECT website (www.aect.org). The standards also are available in book form from AECT. Both publications also include the sample rubrics.

A major goal for the Standards is to have them widely disseminated and adopted globally by various organizations 
and institutions of higher learning. As this occurs, AECT will realize its vision of becoming the premier international organization in educational technology.

\section{References}

AECT (2018). AECT strategic plan. Bloomington: Association for Educational Communications and Technology.

CEN-CENELEC (2018). The importance of standards. The European Committees for Standardization and Electrotechnical Standardization. Retrieved from https://www.cencenelec.eu/ research/tools/ImportanceENs/Pages/default.aspx.

Harris, P. (2017). Foreword. In A. A. Piña (Ed.), Instructional design standards for distance learning. Bloomington: Association for Educational Communications and Technology.
Klein, J. D., Spector, J. M., Grabowski, B., \& de la Teja, L. (2004). Instructor competencies: Standards for face-to-face, online and blended settings. Charlotte: Information Age Publishing.

Kozalka, T. A., Russ-Eft, D. F., \& Reiser, R. A. (2013). Instructional designer competencies: The standards (4th ed.). Charlotte: Information Age Publishing.

Online Learning Consortium. (2018). OLC OSCQR course design review scorecard. Retrieved from https://onlinelearningconsortium.org/ consult/oscqr-course-design-review/.

Piña, A. A. (Ed.). (2017). Instructional design standards for distance learning. Bloomington: Association for Educational Communications and Technology.

Piña, A. A., \& Bohn, L. (2014). Assessing online faculty: More than student surveys and design rubrics. Quarterly Review of Distance Education, 15(3), 25-34.

Quality Matters. (2014). Higher ed course design rubric standards $\left(5^{\text {th }}\right.$ Ed.). Retrieved from https://www.qualitymatters.org/qa-resources/ rubric-standards/higher-ed-rubric. 